strued to interfere with the reception and treatment of acute cases of insanity in chartered general hospitals, in the same manner and under the same conditions as patients suffering from other diseases are there received and treated, provided such hospitals have suitable accommodations approved by the State Commission in Lunacy.

\begin{tabular}{|c|c|}
\hline \multirow[t]{2}{*}{ (Signed) } & $\begin{array}{l}\text { FREDERICK PETERSON, } \\
\text { Chairman. }\end{array}$ \\
\hline & $\begin{array}{l}\text { C. L: DANA, M.D., } \\
\text { RALPH L. PARSONS, M.D., } \\
\text { GEO. W. JACOBY, M.D., } \\
\text { Ex-officio. }\end{array}$ \\
\hline
\end{tabular}

\title{
gexiscopre.
}

BY E. P. HURD, M. D, LOUISE FISKE.BRYSON, M. D., W. W. SKIN. NER, M. D, GRACE PECKHAM, M.D., AND ISAAC OTT, M.D.

\section{DELIRIUM TREMENS.}

At a recent meeting of the Imperial and Royal Society, of Vienna, (Jan. Ioth, I 890 ), the subject of delirium tremens was discussed.

PROFESSOR MEYNERT regarded this morbid entity as the result of a slow and chronic poisoning of the organism by alcohol. The attack is always preceded by great excesses in the use of spirits or absinthe; it may also be provoked by sudden suppression. It seldom comes on spontaneously, being generally the accompaniment of an intercurrent affliction: an hæmoptysis, a pneumonia, a pleurisy, an epileptic fit, a traumatism; simple mental emotion may serve as an exiting cause. In this respect it resembles the onset of hydrophobia.

Delirium tremens presents a march of extreme regularity. Two distinct periods in its evolution are recognized. In the first, or period of anguish, the patient is a prey to an intense delirium of persecution; unlike other deliriums of the same nature, the danger which threatens the individual suffering from delirium tremens is immediate. The 
patient is afraid of being killed by thieves, and to escape the danger which is impending, he will sometimes attempt suicide. This period of anguish lasts about three days; to this succeeds the second period or that of hallucinations and restless dreams. These toxic hallucinations may be of central or peripheral origin, and in the latter case, they are due to the noxious influence of the blood on the peripheral nerves. The patient thinks that he holds in his hands divers objects such as iron, glass, etc. These tactile hallucinations are generalized to the whole surface of the body.

Among the multiple hallucinations of sight, the most frequent is the vision of small objects: mice, rats, beetles, etc. Others see horrible little spectres, hobgoblins, witches glaring at them. Skuda attributed these phenomena to scotomata. It is true that these hallucinations call to mind the scotoma by three definite forms.

It is no less true that the vision of small objects is sometimes wanting, and the patient sees instead of rats and mice, great troops of elephants, or bands of soldiers leaping over a wall and approaching him. Scotomata cannot explain this kind of hallucinations. At the same time, the appreciation of greatness and of volume varies even in the normal state; the patient may then interpret after his own manner the dimensions of images due to scotoma. The hallucinations of delirium tremens are never stable; they are almost always mobile. This phenomena finds its explanation in the fact that the poisoned blood acts continually on the nerve centres, and keeps awake the notions of detail stored up in the cerebrum. The attack ends by a sort of agitated dream and "professional" delirium.

Hallucinations of smell and taste are frequent; the patients complain of perceiving bad odors, or of their food having a detestable taste. The hallucinations of hearing are more marked than those of sight; the patient hears abusive epithets reproaches, obscence propositions, etc.; there are multiple voices, and every word is a menace.

In the discussion which followed, Exner declared that he had been a pupil of Skoda, but did not know that the latter attributed to scotomata the hallucinations of delirium tremens. He (Exner) believed that these phenomena are referable to unequal and abnormal excitations of the retina by vitiated blood.

*

With regard to the therapeutics of delirium tremens, (which we believe was not touched upon at the meeting aforesaid), it is doubtful if anything has yet been discovered 
to supersede the hypnotic and supporting treatment by chloral, opium, capsicum, nutrients, and occasionally, to meet special indications, but only for temporary effect, alcohol. I have been inclined to regard delirium tremens as a form of alcoholic paralysis, analogous to the tremblement mercurial of the French pathologists, due to saturation of the nerve cells of the cerebral cortex with the poison, and consequent enfeeblement and perversion of the sensory, peraptive, and motor functions. The tremulousness of the voluntary marches, the tongue, the members; the vain attempts of the inebriate to escape his pursuing spectre, which generally takes on the form of vermin, reptiles, or the most grotesque and unnatural objects; the haggard, distressful expression of the patient, who can obtain no sleep or rest, and whose languishing organic functions testify to the oppression of the nervous and vital forces, all constitute a pathological syndrome which is peculiar to the disease in question. Doubtless the poison should be at once withdrawn, but in some cases a tapering-off method is certainly preferable to a sudden, complete withdrawal, (though such cases are comparatively few), and there are others where a temporary failure of the heart makes the exhibition of a little alcohol imperative. Sleep is undoubtedly the great restorative, and to procure this recourse must be had to some hypnotic. I believe that experience has proved that chloral is much better and safer than opium. The combination of half a grain of morphine and twenty grains of chloral in violent cases is a good one. Chloral will sometimes be borne in very large doses. It is a good thing to associate with capsicum, which is a stimulant to the gastric expansions of the vagi nerves, and indirectly to the cerebro spinal centres, of great and immediate efficacy. Dr. Kinnear, of Portsmouth, England, used to give scruple boluses of powdered capsicum every two or three hours. Patients in less than an hour after swallowing the bolus, would fall into a quiet sleep, from which in three or four hours they would awake "calm, conscious and convalescent."

I have given capsicum in connection with chloral in the form of the tincture, the dose being twenty drops. Its sustaining influence on the nervous centres seems to be marked, and it tends to counteract any depressant effect of chloral on the heart.

According to Dujardin Beaumetz, (see his book "New Medications," translated by me, page 263 ), paraldehyde is a better hypnotic in delirium tremens than chloral. The 
dose is a teaspoonful as often as required to produce sleep.

Urethan has appeared to me too feeble a hypnotic to be of any utility in delirium tremens, and I believe that the same remark is applicable to sulphonal and somnal.

As for nutrients, milk, meat broths, the meat extracts, and other of the protein preparations in the market, are all indicated in such quantities as the generally inflamed stomach of the inebriate will tolerate. Desiccated blood (P., D. \& Co., Detroit), is a useful alimentary food product when a powerful and easily assimilated nutrient is demanded.

Lately a new treatment of delirium tremens by large doses of strychnine has been recommended. To Laton, of Rheims, we are indebted for this therapeutic novelty. Laton advised doses of five milligrammes (one twelfth of a grain) by hypodermic injection, or by mouth; these doses to be repeated twice or three times a day. Dujardin Beaumetz has repeated the hospital experiments of Laton with uniformly good success. By experiments on animals, Beaumetz has found "that there exists within certain limits a real antagonism between the action of alcohol and strychnine." Drs. Journet and Bounard also report favorable results from a series of trials in private practice of this reme$\mathrm{dy}$ in delirium tremens, and in a number of the Bulletin Gineral de Therapeutique for 1888 , appears an article by a Brazilian physician, Ramos, "On the employment of strychnine in delirium tremens," in which he extols the effects of this remedy. He declares strychnine superior to all other remedies, morphine, chloral, paraldehyde, etc., in controlling the disordered manifestations of alcoholism. Strychnine, in his belief, "has in these cases, a substitutive action on the nerve centres, thus antagonizing the excital action of the alcohol." Ramos would give large doses, hypodermic injections of one-twelth of a grain, repeated every four or five hours, till the insomnia, agitation and delirium are mitigated or disappear. In some cases, he does not hesitate to push the remedy till as much as a grain is given in the'twenty-four hours.

E. P. H.

\section{THE ELECTRICAL RESISTANCE OF THE HUMAN BODY.}

("Rivista Sperimentale di Freniatria e di Medicina Legale," vol. xv., fasc. ii.-iii., 1889, p. 226 . Observations by Dr. B. Silva and B. Pescarolo.)

The following are the conclusions given by these authors, after a long and able article on this subject :

1. The electrical resistance of the human body to the 